Anna Mazur

Ph.D. Student, Warsaw School of Economics, Poland

Zaur Phutkaradze

Faculty of Organization and Logistics of Maritime Transportation, Batumi State Maritime Academy, Georgia

Jaba Phutkaradze

Ph.D. Candidate, Warsaw School of Economics, Poland

\title{
Economic Growth and Environmental Quality in the European Union Countries - Is there Evidence for the Environmental Kuznets Curve?
}

\begin{abstract}
This research empirically explores the relation between carbon dioxide emission and economic growth during the period 1992-2010, using panel data on the European Union countries. Both fixed and random effect models are employed to test the Environmental Kuznets Curve (EKC) relationship between $\mathrm{CO}_{2}$ emissions and GDP per capita. While no U-shaped EKC was confirmed empirically for all 28 current EU member states, the graphical analysis demonstrates a justified turning point for $\mathrm{CO}_{2}$ emissions as GDP per capita reaches the level of 23,000 USD. Furthermore, there is a firm empirical ground for the EKC hypothesis based on data from 16 older, relatively high-income EU states. Thus, though not empirically confirmed, there is ample data verifying the existence of the EKC in EU economies.
\end{abstract}

Keywords: Environment Kuznets Curve (EKC), carbon dioxide emission, economic growth, GDP per capita, the European Union

JEL: O10; O52; Q50; Q53 


\section{Introduction}

Technological progress and the industrial revolution have played a crucial role in the world's evolution and economic growth, but are also associated with environmental destruction. Indeed, human activities have increased greenhouse gas emissions by $70 \%$ in the last 30 years of the $20^{\text {th }}$ century [IPCC, 2007, p. 36], and the global concentration of atmospheric $\mathrm{CO} 2$ e by $35 \%$ between the pre-industrial period (1750) and the beginning of the $21^{\text {st }}$ century [p. 37]. On the one hand, these statistics motivate policy makers to take protective measures. On the other hand, legislators should require scientific evidence to justify environmental curbs on economic activity. These two parallel tracks on the question of whether economic development correlates with environmental quality.

Concerning economic development, world "GDP trends have been very positive" [Carreras, 2006, p. 6], especially throughout the last century. However, an unresolved question is whether economic growth (measured, inter alia, by GDP growth) is positively correlated with environmental destruction (measured, inter alia, by $\mathrm{CO}_{2}$ emissions). In other words, will the proportion of $\mathrm{CO}_{2}$ in the atmosphere and GDP per capita continue to grow simultaneously?

When it comes to the environment, it may be argued that economic development may, over time, decrease $\mathrm{CO}_{2}$ emissions (however purposefully or indirectly) through technological progress by creating production chain and technologies that cause less damage to the environment generally, and the atmosphere in particular.

Many economists have explored the relationship between various indicators of environmental quality and economic progress during recent decades. Grossman and Krueger introduced the so-called Environmental Kuznets Curve (EKC) model [1991]. They considered in their work correlations between different environmental quality indicators (including $\mathrm{CO}_{2}$ emissions) and income per capita. The central thesis a of the EKC is that environmental degradation should stop at some point in a country or region's economic growth. Using the EKC, the authors describe an inverted U-shape relationship between per capita income and environmental quality indicators.

European Union (EU) countries offer an opportunity to empirically analyze the EKC hypothesis, because the $\mathrm{EU}$ is one of the most regulated and developed regions in the world, characterized by relatively high-incomes and economic stability, as well as strengthened environmental protection rules. In 2007, all EU member states adopted a new law intended to reduce carbon dioxide emission by $20 \%$ (from $1990 \mathrm{~s} \mathrm{levels}^{1}$ ) by 2020 . These factors would appear to be particularly relevant when considering the premise that the "cost of environmental degradation does not necessarily increase in rich countries or households" because of higher consumption levels resulting from increased incomes [Giovanis, 2012, p. 603]. 
In this paper, we explore whether there is an inverse U-shaped relationship between economic growth and environmental quality indicators in the EU during the 1992-2010 period. To do so, we test the EKC hypothesis using a regression analysis that employs data for all 28 countries, and then test the model for the 16 countries which joined the EU prior to 2004. This second step is taken to account for the possibility that countries joining the EU from 2004 onwards were developing economies with lower incomes per capita. Both a fixed effect and a random effect model were applied to conduct a panel data analysis, as advocated by Park [2009] and some other authors.

\section{Literature Review}

Accelerating technological progress and improving economic mechanisms have long been targets for policy makers and regulatory authorities. This is especially true when progress relates to environmental quality. There is a strong drive to enhance economic growth and protect the environment. These two goals are strongly correlated, especially in developing countries where economic growth is closely tied, inter allia, with energy producing activities, which escalates pollution emission. A considerable number of studies link particular pollutants and various agents of economic growth. In this article the focus is on carbon dioxide emissions and GDP per capita in the European countries.

The theoretical foundations of the correlation between $\mathrm{CO} 2$ emissions and GDP per capita lie in the EKC concept. Simon Kuznets hypothesised that along the process of economic growth, various market agents initially increase and then decrease over time. The hypothesis originally referred to levels of economic inequality and the shift from industrially underdeveloped economies to industrialized ones. Kuznets advocated the notion that there is "a long swing in the inequality characterising the secular income structure: widening in the early phases of economic growth when the transition from the pre-industrial to the industrial civilisation was most rapid; becoming stabilised for a while; and then narrowing in the later phases" [Kuznets, 1955, p. 18]. Thus, the phenomenon might be depicted as a U-shaped curve. Up to some level the value of one variable in correlation to another rises until reaching a particular level, when it drops.

Although Kuznets' curve was initially unsupported empirically, the U-shaped curve has been the subject of numerous analyses. Since Grossman and Krueger [1991] applied the U-shaped curve to access the level of environmental quality (and ecological degradation in particular) there have been many references to the Environmental Kuznets Curve. Grossman and Krueger studied the Environmental Kuznets Curve for a number of pollutants in the context of the North American Free Trade Agreement (NAFTA). They made a number of observations regarding differences in environmental damage in relation to territorial and governmental agents, such as that: " $\mathrm{SO}_{2}$ pollution has been significantly greater in cities located in Communist-ruled countries," [Grossman, 1993, p. 13] and that 
the extent of environmental destruction may depend on whether "competitive advantage derives largely from differences in environmental regulation" [Grossman, 1993, p. 15]. A recent empirical analysis of the Malaysian economy indicates that "international trade is disastrous to the environment" [Lau, 2014, p. 496]. Such implications may become a foundation for particular public policy recommendations advocating greater emphasis on local export-oriented industries.

\section{The EKC Support}

Ample contributions to the issue in question come from research done in numerous countries, regions, or continents. However, in order to maintain the proper scope of the arguments presented here, the paramount non-European works both, corroborating and refuting the EKC hypothesis, are referred to here, and the main emphasis in the literature review will be on similar contributions on the European scene.

The analyses of the EKC against various indicators of environmental quality did not confirm a uniformly positive correlation across countries and regions as "different countries exhibit different patterns for their relationships between environmental quality and economic growth" [Onafowora, 2014, p. 48]. Nevertheless, some economists have demonstrated that after economic development reaches a predefined point, environmental degradation starts to decline.

Holtz-Eakin and Seldin [1992] integrated $\mathrm{CO}_{2}$ into their research by using panel data analyses from 130 countries for the period of 1951-1986. Their work exposed a turning point of 35,000 USD GDP per capita, at which $\mathrm{CO}_{2}$ emissions should stop escalating and begin decreasing.

The next path breaking research was done for the 1992 World Development Report by Shafik and Bandyopadhyay [1992]. They investigated the EKC for 10 different environmental quality indicators: carbon dioxide emissions, municipal waste, deforestation, sulfur oxides, etc., for 149 countries during the 1960-1990 period. These authors demonstrated a significant relationship between all the observed environmental degradation indicators and income per capita. They validated the EKC hypothesis with regards to local air pollutant concentrations, and argued that the reflection point is reached when income per capita lies between 3,000-4,000 USD. They also identified a strong positive link between $\mathrm{CO}_{2}$ and income growth.

Two years after their first work, Grossman and Kruger [1993] investigated the linkage between environmental quality and GDP per capita in the NAFTA countries (Canada, Mexico and the USA). The authors estimated that the turning points for $\mathrm{SO}_{2}$ and dark matter emissions are at approximately 4000-5000 USD income per capita (year 1985), at which point become more concerned about their surrounding atmosphere. If we assume 
per capita income continues to growth and the general well-being of citizens continues to improve, people might start participating in various activities to protect/improve their environment, leading to a cleaner environment.

After the first attempts of Grossman \& Krueger [1991] and Shafik \& Bandyopadhyay [1992], the relationship between various pollutants and economic growth has gained prominence among researchers, including Beckerman [1992], Selden and Song [1993], Panayotou [1993], and Shafik [1994]. These authors reached differing results: some supported the EKC concept; others denied its existence or stipulated that the EKC did exist for only selected pollutants [Stern, 2005]. The perennial problem in most of these studies was a lack of empirical evidence for the more complex debates related to a steady-state economy or the link between technological progress and natural resources exploitation [Cialani, 2007, p. 568].

One of the first economists to defend the EKC and argue that the quickest way to become environmentally clean is through economic advancement was Wilfred Beckerman. He believed that higher income per capita should result in more awareness of the need for environmental protection. In other words, as people acquire wealth they become more concerned about their living conditions which are directly affected by the quality of the environment. Beckerman [1992, p. 491] asserted that "the strong correlation between incomes and the extent to which environmental protection measures are adopted demonstrates that in the longer run, the surest way to improve your environment is to become rich". Beckerman also made the point that might be one of the controlling arguments in this discussion, namely that "developing countries are unlikely to replicate precisely the environmental histories of developed countries" [1992, p. 1].

Another economist who, early on, investigated the U-shaped relationship between environmental quality indicators and economic growth was Panayotou [1992, 1993, 1995]. Panayotou verified the existence of the EKC concept in the ECE countries (over 50 member states of the United Nations Economic Commission for Europe from Europe, Asia and North America), examining how successful given countries were in encouraging environment protection along with economic growth. The analysis was deepened by application of structural or technological changes and policy mechanisms in both economic environments: the developed market and markets in transition. European, in comparison to Asian, countries were generally defined as "the very wealthy countries" [2003, p. 30] with incomes thirty times greater than that of the poorest ECE member, such as Tajikistan. The author observed that when a particular variable's pollution prices (e.g., SO2 emissions) were closer to their marginal social costs, the turning point in the inverted U-shaped curve was visible at considerably low income levels. For carbon dioxide, the turning point of the Kuznets curve was either at a much higher income level or was not observed at all. This conclusion was supported by the argument that environmental damage from $\mathrm{CO}_{2}$ - being less immediate and evident - was undervalued to the point where its price is not estimated. 


\section{Critique and Alternatives}

A major critique of the EKC is, as Stern declared, that "the EKC is an essentially empirical phenomenon, but most of the EKC literature is econometrically weak" [2003, p. 1]. Shafik [1994] did not find any confirmation of the $\mathrm{EKC}$ for $\mathrm{CO}_{2}$, but did discover a positive dependence between income and $\mathrm{CO}_{2}$ emission - an increase of income by $1 \%$ should result in $1.62 \%$ increase in $\mathrm{CO}_{2}$ release.

Dijkgraaf and Vollebergh [2005] also questioned the general application of the EKC, arguing that economic growth and environmental exploitation are both correlated with the level of fossil fuel use and, especially, price. A reasonable concern arises upon acknowledging that "economic growth calls for increased use of energy for which, in the short to medium term, there are no credible sources other than fossil fuels" [Hannesson, 2009 , p. 157], at least not yet.

M'Henni [2005] reported no evidence of the EKC with regard to pollutants in underdeveloped Tunisia, where "the environmental question is prioritized politically and economically” [M'Henni, 2005, p. 342-349]. One conclusion reached is that on a regional level "in the long-run energy consumption has a positive significant impact on $\mathrm{CO}_{2}$ emissions", at a broader level the EKC is not validated. Moreover, the relationship was unsatisfactorily supported as "EKC turning points are very low in some cases and very high in other cases, hence providing rather poor evidence in support of the EKC hypothesis" in general [Arouri, 2012, p. 347].

A slightly different approach, but still counter-argumentative approach to the EKC, was offered by Dietz [2012, p. 12], that is, "the EKC oversimplified complex relationships by focusing exclusively on economic development". Other criticisms related to possible development of the curve's shape. Some economists have suggested an N-shaped curve as an alternative to the EKC, meaning that atmospheric contamination would again increase after the second changing point. For example, De Bruyn, et al. [1998] suggested that an inverted U-shaped relationship between economic growth and environmental degradation indicators is not sustained over the long-run. Instead, this relationship exists only at the initial stage, after which a new tipping point would lead to the $\mathrm{N}$-shaped curve. The environmental $\mathrm{N}$-shaped relationship between per capita emission of $\mathrm{SO}_{2}$ and per capita GDP was also confirmed by Fodha and Zaghdoud [2010] for Tunisia. Nevertheless, the concept of the $\mathrm{N}$ shape is marginal in this discussion and was only used here as an example of an alternative to the inverted U-shaped relationship. 


\section{The European Reference}

The European aspect of the matter has also been extensively studied. Alvaro, Marrero and Puch [2005] are among those who have debated the promotion of green policies, defining determinants of $\mathrm{CO}_{2}$ emissions and the consequences of the continuous economic growth. These authors analyzed the EU 15 countries, (all 15 members as of 2003, excepting Luxembourg) plus five subsequent members: Hungary, Poland, Czech Republic, Slovakia and Slovenia. Data selection was based on data availability, using each country's annual report between 1990 and 2000 on pollution $\left(\mathrm{NO}_{2}, \mathrm{SO}_{2}, \mathrm{CO}_{2}\right)$, income, and population. These data revealed that air pollution decreased in the $1990 \mathrm{~s}$ in most EU countries, and that states with greater initial level reduced it more rapidly than did countries with initially lower emissions.

The results concerning $\mathrm{CO}_{2}$ revealed different trends for middle-income (the EU14, minus Greece, Ireland, Portugal and Spain) and low-income countries, based on the fact that low-income countries were at a lower level of development in the $90 \mathrm{~s}$, which affected the subsequent shape of the curve. For the former countries output growth is more intensely correlated with pollution growth in general. Nevertheless, "there is no evidence that income dynamics play a role in pollution dynamics" at the macroeconomic level [Alvarez, 2005, p. 13]. It actually does in case of $\mathrm{CO}_{2}$ for the middle-income states, especially when their data is excluded from the analysis. The authors also conclude that there is considerable disparity between variables across countries, which may result from region-dependent levels of economic growth and output rates. Moreover, the influence of environmental policies and $\mathrm{CO}_{2}$ emission targets proved to be "statistically significant and economically important" [Alvarez, 2005, p. 23], even though CO2 emissions are more difficult to control than other pollutants.

In European and non-European studies results there is a considerable heterogeneity between environmental destruction agents, territories (not only single states, but also regions and various groups of countries), and economic growth variables. The main source of the divergence may be linked to the rate of the production growth and territorial specificities. Therefore, it appears that the greater the research population, the weaker the EKC hypothesis.

Marrero, in a 2009 paper, examines a particular aspect of the EKC, that is, that most economic growth and environmental quality models focus on emissions and economic activity while omitting the role of energy production or use as a variable. The author fills this gap using data on 24 European states for 1990-2006 period, concluding that the EKC does not hold statistically, there is conditional convergence of air pollutants, and the curve of greenhouse gas emissions and energy (both, use and production) is inelastic, that is, insensitive to changes. Additionally, the author advocates turning to renewable sources of energy, which would reduce air pollution in per capita terms. 
Among the numerous works on the EKC hypothesis in European countries there is a paper by Donfouet, et al. [2013] which presents aspects of a neglected, controversial issue concerning air pollution estimates within administrative boundaries. That aspect is spatial interdependence, and the source of controversy is that territorial interdependence is the primary cause of biased results. In other words, one country's emission of $\mathrm{CO}_{2}$ accounts for the other country's pollution. The data scope (especially the time period) was extensive relative to other EKC studies, covering 15 European countries during the 1961-2009 period. Besides confirming that the level of $\mathrm{CO}_{2}$ emissions in Europe has been constantly increasing, the authors also provide evidence that increased $\mathrm{CO}_{2}$ emissions in a particular country affect $\mathrm{CO}_{2}$ emissions estimates in neighbouring states. A crucial point here is that the authors "still found statistical evidence of an inverted U-curve between $\mathrm{CO}_{2}$ emissions and per capita income after controlling for spatial interdependence" [Donfouet, 2013, p. 14]. Although this finding is unsurprising, the statistical proof underlying it is an important tool for European Union policy makers who support stricter mandatory $\mathrm{CO}_{2}$ emission regulations.

As appears above, the relationship between economic growth and environmental quality indicators varies according to time period and country/region analyzed, which may explain why some economists have supported the existence of the EKC, while others questioned it. This longstanding dispute suggests the need for more direct empirical research concerning emission growth. At the same time, Donfouet's findings are a strong reminder of EKC analysis limitations when applied to a particular country in the EU.

It is expected, that these results will support the EKC theory, as the majority of the EU countries have already reached their potential. Thus, further economic growth in the EU should decrease the emission of pollutants.

\section{Empirical Analysis}

\section{Methodology and Data}

The EKC is a hypothesised relationship between various indicators of environmental degradation and the level of economic development. Various indicators, such as pollution or energy consumption (not a measure of degradation) tend to worsen, along with economic progress, until a certain threshold level of income per capita is reached, after which the trend reverses. That is, at high-income levels economic development triggers improvements in the quality of environment. Thus, the primary claim relating to the EKC hypothesis is that pollution rises at the early stage of industrialization and then declines in an inverted U-shaped pattern in more developed and industrialized countries as incomes rise [Seldon and Song, 1994; Rosser et al., 2006]. 
The EKC hypothesis is explained by two key factors: wealthier individuals "demand superior environmental quality because their more pressing needs are already met" [Torras, 2005, p. 1354], and richer economies can afford to meet this demand through more environmentally friendly investments and apply more restrictive environmental standards. As Komen [1997, p. 509] argues, besides income per capita and environmental degradation a number of other specific components determine the EKC, such as technical development and scientific research. Investment in new technologies diagnoses, and helps solve, environmental problems. And over the course of economic development, rising levels of innovation increases environmental quality, as well. "Public spending on environmental research and development can also be a catalyst for private spending on developing cleaner technologies" [Komen, 1997, p. 506].

Usually, the EKC is depicted as a relation between GDP per capita and specific environmental indicators. A commonly accepted independent variable in most models is income per capita ${ }^{2}$. Three functional specifications for carbon dioxide emission have been described in the literature for the EKC hypothesis: a linear, a quadratic (inverted U) and a cubic specification (N-shaped). A standard EKC regression model is quadratic (inverted U). According to Stern, et al. [1996] and Panayotou [1993], what leads to environmental quality growth are, inter alia: great economic growth, structural changes into IT-oriented industries and services, as well as expanded environmental awareness, enforcement of environmental regulations, better technology and higher environmental expenditures.

In this study the EKC is used to examine correlations between emissions per capita and GDP per capita in the European Union countries. We apply $\mathrm{CO}_{2}$ as a measure of pollutant and GDP as an independent variable for 1992 to 2010 times series to test whether there has been an inverted U-curve relationship for $\mathrm{CO}_{2}$ emission and GDP across that time period. Data for $28 \mathrm{EU}$ countries is used. While, for some countries, data on our variables of interest is available from 1960, others did not publish any relevant data before 1992. We begin our analysis from 1992 because it was the first year after the dissolution of the Soviet Union (December 25, 1991), the end of Communism in many East European countries, and the beginning of their progression towards the EU. The core contribution to this empirical study is the fact that our analysis was based on a long time series, which allowed us to analyse cross-country data through several phases of development ${ }^{3}$.

The measure of the dependent variable is per capita carbon dioxide emissions ( $\mathrm{C} 02$ emissions), which is known to be the most important anthropogenic greenhouse gas (GHG) in terms of global warming impact. According to the World Development Indicators dataset (WDI), which contains annual information for a large panel of countries, "carbon dioxide emissions are those stemming from the burning of fossil fuels and the manufacture of cement. They include carbon dioxide produced during consumption of solid, liquid, and gas fuels and gas flaring". Income is measured by GDP per capita, PPP (constant 2005 international dollars). 


\section{Model Specification}

Most of the studies seeking empirical evidence in support of the EKC hypothesis share some common characteristics with regards to the data and methods applied. A generally accepted functional model (which we also use in our research) for testing the EKC hypothesis is estimation of a standard polynomial relationship between carbon dioxide $\left(\mathrm{CO}_{2}\right)$ emission and GDP. We take logs on both sides of the equation for a more meaningful interpretation in terms of the rate of change. We model the relationship as follows:

$$
\ln (E)=\alpha i+\gamma t+\beta 1 \ln (G D P) i t+\beta 2 \ln (G D P)^{2} i t+\varepsilon i t \quad[\text { Stern, 2014, p. 6] }
$$

where $\mathrm{E}$ is the environmental indicator $\left(\mathrm{CO}_{2}\right.$ per capita) and GDP is income (GDP per capita), ln indicates natural logarithms, $\alpha$ and $\gamma$ are intercept parameters that vary across countries $i$ and years $t, \beta$ is the coefficient of the explanatory variables and $\varepsilon$ it is an error term. There exists the hypothesis that income elasticity is common to all countries at a particular income level. At the same time, the volume of pollution per capita varies between countries at any individual income level. To analyze time varying omitted variables and stochastic shocks that are typical to all economies, time specific intercepts are used [Stern, 2014, p. 6].

The main purpose for including the squared GDP in the model is to support an assertion that there is an inverted $\mathrm{U}$-shaped curve between income and $\mathrm{CO}_{2}$ per capita. The theoretical expectation is that the coefficient that accompanies this variable is negative and significant. Since the estimation methodology applied in our analysis incorporates panel data, ordinary least squares (OLS) estimation could be inappropriate. OLS estimation would lead to biased results as it assumes a single set of slope coefficients and one intercept. It is common in the economic literature to use fixed effect and random effect models to conduct panel data analysis [Stern, 2003; Park, 2009]. The major difference between the fixed and random effect models is the function of dummy variables. In a fixed effect model, the dummies are considered as a part of the intercept, while in a random effect model, the dummies function as an error term. We employ the fixed effect estimation model, as it is more appropriate for accounting for country-specific effects. The fixed effect model distinguishes individual specifications of the countries by allowing different intercepts for each country in the estimation process. The fixed effect model treats the ai and $\gamma \mathrm{t}$ as regression parameters. The fixed effect model uses least squares dummy variable (LSDV) and within effect estimation methods. We also apply a random effect model analysis. The random effect model assumes the same intercept and slopes while testing the variance components for the countries (or times) and errors. In the random effect model differences between countries (or time periods) are reflected in the variance of the error term, not in the intercept. The random effect model is estimated by generalized least squares (GLS). The fixed effect model is examined by the F-test, while the random effect model is observed by the Wald test. 
We also conducted the Hausman specification test [Hausman, 1978] to see which of the models was more appropriate. According to the Hausman test, if a null hypothesis that individual effects are uncorrelated with other regressors in the model is not rejected, a fixed effect model will not be a consistent estimator. In such circumstances, a random effect model is our preferable estimator.

\section{Empirical Results}

\section{EKC Preliminary Results}

Figures 1 and 2 demonstrate the graphic presentation of the relation between GDP per capita and carbon dioxide emission. Based on figures 1 and 2 it seems that, although there are some deviations, the typical inverted $\mathrm{U}$-form of the EKC is confirmed with our data set. The upper part of figure 1 shows the relation between GDP and carbon dioxide emissions for Luxembourg, which has highest GDP per capita relative to other EU countries. Luxembourg demonstrates a decreasing relationship between our variables of our interest, assuming that the emission of carbon dioxide per capita in this country has already reached its maximum level. It confirms the EKC hypothesis.

FIGURE 1. Carbon dioxide $\left(\mathrm{CO}_{2}\right)$ emissions (metric tons per capita) and GDP per capita (current USD) for the European Union countries, 1992-2010

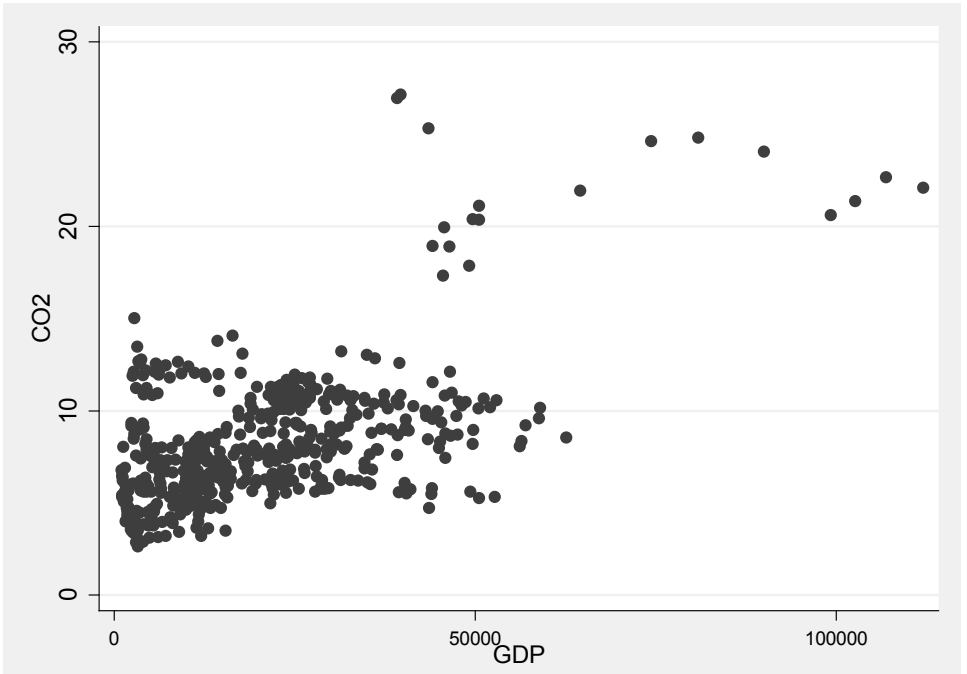

S o u r c e: World Development Indicators. 
Figure 2 depicts the closer view of the lower part of figure 1. Figure 2 graphs the correlation between GDP per capita and $\mathrm{CO}_{2}$ emissions for the rest $27 \mathrm{EU}$ countries, excluding Luxembourg. Figure 2 shows that the inverted U-shape of the EKC might be quite realistic for the European Union. Carbon dioxide emission volumes show a mostly upward trend when GDP per capita is low, until achieving a reflection point (which is approximately 23,000 USD), when it demonstrates a decreasing tendency. This supports the inverted U-curve of the EKC hypothesis in the EU for the period of 1992-2010. In order to confirm whether the EKC holds for the EU, we applied a series of econometric analyses and tests.

FIGURE 2. Carbon dioxide ( $\left.\mathrm{CO}_{2}\right)$ emissions (metric tons per capita) and GDP per capita (current USD) for the European Union countries excluding Luxembourg, 1992-2010

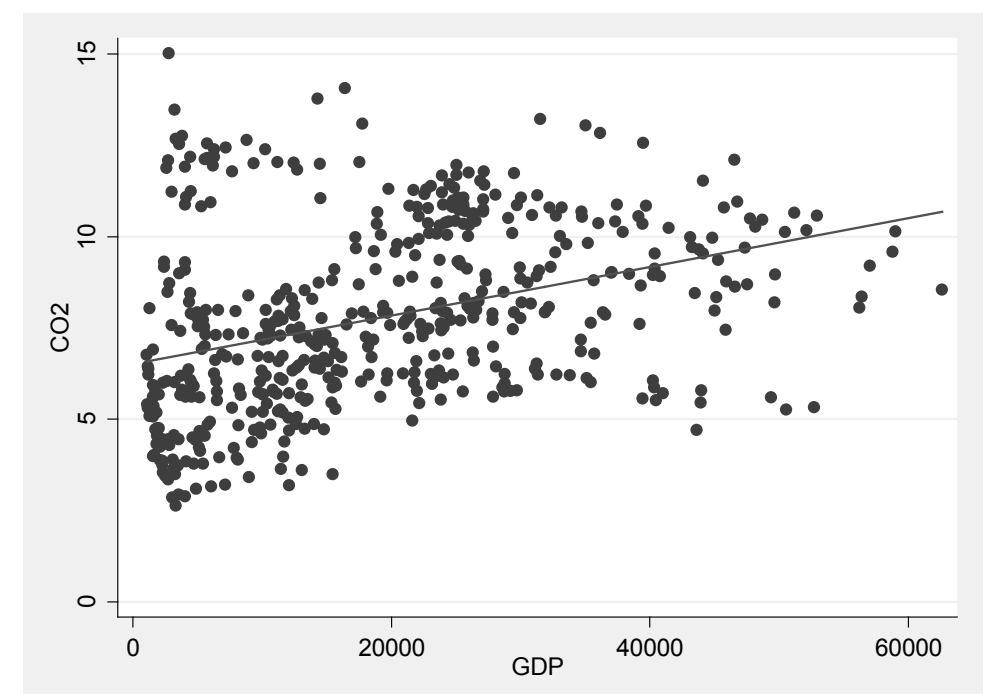

S o u r c e : World Development Indicators.

\section{The Econometric Model}

Tables 1 and 2 show the regression results of both the fixed effect and random effect models for the period 1992-2010 for 28 EU countries. First of all, the probability value for the F-test for the fixed-effect model and the Wald statistics for the random effect model is significant. It means that all the coefficients of our model do not equal zero. Thus, according to the F-test and the Waldtest, all model estimates fit the data well. 
Both models (ignoring the size of coefficients) demonstrate similar outcomes. Based on tables 1 and 2 we can reject the existence of an inverted $U$ relationship, since the estimated t-ratio of the GDP quadratic term is not significant at 95\% significance level tested. Thus, according to our findings, it seems that the typical inverted U-curve of the EKC may not be fully verified with our data set for the European Union. According to the Hausman test $\left(\mathrm{chi}^{2}(2)=2.10\left[\mathrm{Prob}>\mathrm{chi}^{2}=0.3493\right]\right)$ we cannot reject the null hypothesis stating that a random effect model is better than its counterpart. Thus, the random effect model is our preferred model for the analysis.

TABLE 1. Fixed-effect (within) regression Carbon dioxide $\left(\mathrm{CO}_{2}\right)$ emissions and GDP in the European Union countries, dependent variable: logarithm of Carbon dioxide $\left(\mathrm{CO}_{2}\right)$ emissions

\begin{tabular}{|l|c|c|c|c|c|}
\hline \multicolumn{1}{|c|}{ Variable } & Coef. & Std.Err & $\mathrm{z}$ & $\mathrm{P}>|\mathrm{z}|$ & {$[95 \%$ Conf. Interval] } \\
\hline GDP per capita (logarithm) & .6189628 & .3007817 & 2.06 & 0.040 & .0279324 1.209993 \\
\hline Squared GDP per capita (logarithm) & -.2233146 & .139387 & -1.60 & 0.110 & $-.4972074 \quad .0505782$ \\
\hline Interaction Term & -.0101791 & .0035649 & -2.86 & 0.004 & $-.0171841-.0031741$ \\
\hline
\end{tabular}

Notes: Number of observations 504; Sample period 1992-2010; Number of time periods $(T)=18$; Number of countries $(N)=28$; F-Test $(2,474)=16.17($ Prob $>F=0.0000)$.

Source: own elaboration.

TABLE 2. Random-effect GLS regression Carbon dioxide $\left(\mathrm{CO}_{2}\right)$ emissions and GDP in the European Union countries, dependent variable: logarithm of Carbon dioxide $\left(\mathrm{CO}_{2}\right)$ emissions

\begin{tabular}{|c|c|c|c|c|c|}
\hline Variable & Coef. & Std.Err & $\mathrm{z}$ & $\mathrm{P}>|\mathrm{z}|$ & [95\% Conf. Interval] \\
\hline GDP per capita (logarithm) & .6647767 & .2872051 & 2.31 & 0.021 & .10186511 .227688 \\
\hline Squared GDP per capita (logarithm) & -.2499388 & .1324784 & -1.89 & 0.059 & $-.5095918 \quad .0097141$ \\
\hline Interaction Term & -.0091774 & .0034413 & -2.67 & 0.008 & $-.0159223-.0024325$ \\
\hline
\end{tabular}

Notes: Number of observations 504; Sample period 1992-2010; Number of time periods $(T)=18$; Number of countries $(N)=28$; Wald $\operatorname{chi}^{2}(2)=30.32\left(\right.$ Prob $\left.>\operatorname{chi}^{2}=0.0000\right)$

Source: own elaboration.

Our empirical analysis confirms that $\mathrm{CO}_{2}$ emissions per capita have not yet reached an upper limit as most EU countries are still in a rapid economic growth conditions. Hence, based on the annual data over the period 1992-2010, the $\mathrm{CO}_{2}$ emission per capita have been rising linearly with regards to the growth in the level of GDP. According to our findings, the EKC hypothesis in $\mathrm{CO}_{2}$ emissions has not been supported for the EU so far. Consequently, there is no empirical evidence for untying carbon emission and economic growth in the EU zone. 
On the other hand, it should be noted that, although not significant, the coefficient of the GDP quadratic term is negative for both the fixed effect and the random effect models. Furthermore, the random effect model (the preferred model according to the Hausman test), the probability value for the t-test is 0.59 , which is very close to significant. If we combine the econometric results with the graphical representation, we see that non-significance of the GDP quadratic term is easily explainable. For the 12 countries in our sample GDP per capita is far below the level of 23,000 USD (which is the turning point according to the graphical analysis) ${ }^{4}$. The majority of these countries joined the EU in 2004 or later. In addition, our analyses cover the time period starting from 1992, while the level of 23,000 USD of per capita GDP by some countries was achieved in later periods ${ }^{5}$. Furthermore, it should be mentioned that there have been very recent publications critical of panel data regression analyses. Some economists claim that such studies suffer from econometric weaknesses, biased estimations, and inconsistencies in the panel model results [Schmalensee, et al., 1998; Dijkgraaf and Vollebergh, 2005]. Any (or all) of these reasons may explain why the inverted U-shape of the EKC, which was presented in the graphs, has not been confirmed by our empirical analysis.

In order to check if our reasoning was correct with regards to the 12 relatively new EU member countries we conducted one more test. We performed an analysis of both a fixed effect and a random effect model for the same 1992-2010 period. However, this time we carried out a regression calculation only for the 16 countries which were the relatively older members of the EU and had higher GDP per capita ${ }^{6}$. As before, both models had approximately similar outcomes, however according to the Hausman test $\left(\mathrm{chi}^{2}(2)=0.95\right.$ $\left[\right.$ Prob $\left.>\mathrm{chi}^{2}=0.6215\right]$ ) the random effect model was more appropriate. As we can see from the table 3 , the coefficient of the GDP quadratic term is negative and significant, meaning that an inverted " $U$ " relationship is verified in 16 older EU member countries over the examined period. Thus, these $16 \mathrm{EU}$ countries confirm that at high-income levels economic growth leads to environmental improvement.

TABLE 3. Random-effect GLS regression Carbon dioxide $\left(\mathrm{CO}_{2}\right)$ emissions and GDP in the18 European Union countries, dependent variable: logarithm of Carbon dioxide $\left(\mathrm{CO}_{2}\right)$ emissions

\begin{tabular}{|l|l|c|c|c|c|}
\hline \multicolumn{1}{|c|}{ Variable } & \multicolumn{1}{c|}{ Coef. } & Std.Err & $\mathrm{z}$ & $\mathrm{P}>|\mathrm{z}|$ & {$[95 \%$ Conf. Interval] } \\
\hline GDP per capita (logarithm) & 1.49254 & .5245125 & 2.85 & 0.004 & .46451492 .520566 \\
\hline Squared GDP per capita (logarithm) & -.6686225 & .2505376 & -2.67 & 0.008 & $-1.159667-.1775778$ \\
\hline Interaction Term & -.000995 & .0041449 & -0.24 & 0.810 & $-.0091189 \quad .007129$ \\
\hline
\end{tabular}

Notes: Number of observations 288; Sample period 1992-2010; Number of time periods $(T)=18$; Number of countries $(N)=16$; Wald $\operatorname{chi}^{2}(2)=15.16\left(\right.$ Prob $\left.>\operatorname{chi}^{2}=0.0005\right)$.

S o u rce : own elaboration. 
This leaves us with different data analyses that reach conflicting results about effects of growth on the carbon dioxide emissions. While the empirical analysis of all $28 \mathrm{EU}$ countries did not support the EKC hypothesis, the graphic illustration, did not demonstrate a U-shaped income and $\mathrm{CO}_{2}$ emissions relationship. But, as predicted by the EKC theory, macroeconomic examination of the 16 older and relatively higher income EU countries verified the inverted U-shaped relationship between a specific indicator of environmental quality and per capita income. Thus, our study suggests that the EKC does not hold for the whole EU area over time, but it is proved in a particular pool of individual EU member countries. Therefore, additional single country research over time is needed to verify the progression of environmental degradation relative to GDP, especially for the 12 relatively new EU members.

It should be mentioned that while all EU countries are subject to joint EU environmental policies (both under its own internal target in the Europe 2020 Strategy and under the Kyoto Protocol's commitment), these policies have been translated into national emission reduction or limitation targets that are individual for each country. Each Member State's progress towards meeting its national emission targets, as well as the renewable energy and energy efficiency targets are assessed by the Commission to make country-specific recommendations appropriate. According to the European Commission on climate action, although fifteen older Members States are already projected to reach their commitments to meet the 2020 targets for the non-ETS sectors, 13 Member States still need additional efforts. The 15 countries that were EU members when the Kyoto Protocol was agreed to in 1997 ('EU-15') committed to reducing their collective emissions to 8\% below 1990 levels by the years 2008-2012. The latest emissions monitoring and projections show that the EU 15 is on track to exceed this target EU-15 is on track to over-achieve this target. Of the 13 countries which have joined the EU since 2004, all except Cyprus and Malta have $6 \%$ to $8 \%$ individual emission reduction commitments (5\% in Croatia’s case).

The individual emission reduction targets defined by the Kyoto Protocol and Europe 2020 Strategy are linked to many socio-economic and environmental indicators, such as GDP growth rate, energy consumption, environmental protection expenditures, the $\mathrm{CO}_{2}$ per capita indicator, expenditures on air pollution abatement, etc., which may affect each country's "turning point". However, the fact that the new member countries have to decrease gas emission at lower rates than "old" members supports our assumption that new members have not yet reached a sufficient level of socio-economic development to verify the EKC.

\section{Conclusion}

In this paper we have analyzed the correlation between economic growth and air pollution for the EU area in a historical perspective. Using panel data properties and 
econometrics analysis, we have studied the EKC Hypothesis for all $28 \mathrm{EU}$ states. The empirical investigation for the 1992-2010 period, based on fixed and random effect estimations, does not provide strong evidence that a negative correlation of income is established with carbon dioxide emission levels. In particular, no EKC U-shape was confirmed for the whole EU area. However, examination of the graphical illustration proved the existence of a reasonable turning point for $\mathrm{CO}_{2}$ emissions, which appears at a GDP per capita of approximately 23,000 USD. Furthermore, the EKC effect was consistently negative and statistically significant across the 16 older, relatively high-income EU member countries, providing strong support for the EKC hypothesis in those countries. Our results do not suffice to prove the EKC for the whole data pool and one of the possible reasons is that the level of economic development of the 12 newest EU members is not high enough.

Further individual country-specific research is required in order to confirm that pollution emissions will indeed decrease as predicted by the EKC hypothesis in all EU countries. In addition, to reduce the cumulative emission of carbon dioxide, the EU countries, especially those that joined the union in 2004 and later, should continue to reform their regulations of environmental pollution and concentrate more on structural changes that result in environmentally friendly GDP growth.

\section{Notes}

1 Communication from the Commission to the European Parliament, the Council, the European Economic and Social Committee and the Committee of the Regions - 2020 by 2020 - Europe's climate change opportunity.

2 Some studies use income data converted into PPP (Purchasing Power Parity) or incomes at market exchange rates.

310 countries joined the European Union on 1 May 2004 (Czech Republic, Cyprus, Estonia, Hungary, Latvia, Lithuania, Malta, Poland, Slovakia and Slovenia), the two second-wave accession countries joined on 1 January 2007 (Romania and Bulgaria). Thus, we can investigate at least two phases (before and after joining the European Union) of development of those countries.

4 GDP per capita is below the level of 23,000 USD for the following 12 countries: Bulgaria, Croatia, Czech Republic, Estonia, Hungary, Latvia, Lithuania, Malta, Poland, Romania, Slovak Republic, and Slovenia.

5 23,000 USD level of per capita GDP was achieved in: Cyprus (2004), Greece (2006), Ireland (1998), Italy (2003), Portugal (2008) and Spain (2004).

6 All of the 18 countries had reached 23,000 USD level of per capita GDP prior to 1992, or achieved it in a later period. 


\section{References}

Arouri, M.H., Ben Youssef, A., M'Henni, H., Rault, C. (2012), Energy consumption, economic growth and $\mathrm{CO}_{2}$ emissions in middle east and north African countries, CESifo Working Papers, No. 3726, pp. 342-349.

Azomahou, T., Laisney, F., Nguyen, Van P. (2006), Economic development and $\mathrm{CO}_{2}$ emissions: a nonparametric panel approach, Journal of Public Economics, Vol. 90, Issues 6-7, pp. 1347-1363.

Beckerman, W. (1992), Economic growth and the environment: whose growth? Whose environment?, World Development, pp. 481-496.

Bruyn, J. van den Bergh., Opschoor, J. (1998), Economic growth and emissions: reconsidering the empirical basis of environmental Kuznets curves. Ecological Economics, 25, pp. 161-175.

Cialani, C. (2007), Economic growth and environmental quality, an econometric and a decomposition analysis, Management of Environmental Quality, An International Journal, Vol. 18, No. 5, pp. 568-577.

Álvarez, F., Marrero, G.A., Puch, L.A. (2004). Air pollution convergence and economic growth across European countries, ICAE Working Paper, 0406.

Dietz, T., Rosa, E.A., York, R. (2012), Environmentally efficient well-being: Is there a Kuznets curve?, Applied Geography, 32, pp. 21-28.

Dijkgraaf, E., Vollebergh, H.R.J. (2005), A test for parameter heterogeneity in $\mathrm{CO}_{2}$ panel EKC estimations, Environmental and Resource Economics 32(2), pp. 229-239.

Donfouet, H.P.P., Jeanty, P.W., Malin, M. (2013), A spatial dynamic panel analysis of the environmental Kuznets curve in European countries. Center for Research in Economics and Management (CREM), Economics Working Paper Archive, 2013-18.

European Commission (2007), A European Strategic Energy Technology Plan: Towards a low carbon future, COM (2007) 723.

European Commission (2014) Communication from the Commission to the European Parliament, the Council, the European Economic and Social Committee and the Committee of the Regions. Taking stock of the Europe 2020 strategy for smart, sustainable and inclusive growth. COM (2014) 130.

European Parliament (2007) European Parliament Resolution on Climate Change, P6_TA (2007) 0038.

Farhani, S., Mrizak, S., Chaibi, A., Rault, C. (2014), The environmental Kuznets curve and sustainability: A panel data analysis, Energy Policy, 71, pp. 189-198.

Fodha, M., Zaghdoud, O. (2010), Economic growth and environmental degradation in Tunisia, An empirical analysis of the environmental Kuznets curve, Energy Policy, 38, pp. 1150-1156.

Giovanis, E. (2012), Environmental Kuznets curve: evidence from the British household panel survey, Economic Modelling, 30, pp. 602-611.

Grossman, G.M., Krueger, A.B. (1991), Environmental impacts of a North American free trade agreement, Working Paper, 3914, National Bureau of Economic Research.

Grossman, G.M., Krueger, A.B. (1993), Environmental impacts of the North American free trade agreement, in Peter Garber (ed.), The U.S.-Mexico Free Trade Agreement, MIT Press, Cambridge.

Hannesson, R. (2009), Energy and GDP growth, International Journal of Energy Sector Management, 3(2), pp. 157-170.

Hausman, J.A. (1978), Specification tests in econometrics, Econometrica, 46, pp. 1251-1271.

Heaps, C., Erickson, P., Kartha, S., Kemp-Benedict, E. (2009), Europe's Share of the Climate Challenge Domestic Actions and International Obligations to Protect the Planet, Stockholm Environment Institute. 
Holtz-Eakin, D., Selden, T.M. (1992), Stoking the fires? $\mathrm{CO}_{2}$ emissions and economic growth, NBER Working Paper 4248, National Bureau of Economic Research Inc., pp. 42-48.

IPCC (2007), Climate change 2007: A Synthesis Report. A Contribution of Working Groups I, II and III to the Fourth Assessment Report of the IPCC, Intergovernmental Panel on Climate Change, Geneva.

Kahn, M.E. (2003), New Evidence on Eastern Europe’s Pollution Progress, Topics in Economic Analysis \& Policy, (3), 1.

Komen, M.H., Genking, S., Folmer, H. (1997), Income and environmental R\&D: empirical evidence from OECD countries, Environment and Development Economics, Vol. 2, pp. 505-515.

Kuznets, S. (1955), Economic growth and income inequality, American Economic Review, 49, pp.1-28.

Lau, L.S., Choong, C.K., Eng, Y.K. (2014), Investigation of the environmental Kuznets curve for carbon emissions in Malaysia: Do foreign direct investment and trade matter?, Energy Policy 68, pp. 490-497.

Marrero, G.A. (2009), Greenhouse gases emissions, growth and the energy mix in Europe: a dynamic panel data approach, FEDEAWorking Papers, (16).

M'Henni, H. (2005), Economic development, adjustment and environmental quality, the case of Tunisia for a contingent valuation study, Mediterranean Journal of Economics, Agriculture and Environment, Vol. IVN (2), pp. 342-349.

M'Henni, H., Arouri, M.H., Ben Youssef, A., Rault, C. (2011), Income level and environmental quality in the MENA countries: Discussing the environmental Kuznets curve hypothesis, The Economic Research Forum Working Paper, 587.

Onafowora, O.A., Owoye, O. (2014), Bounds testing approach to analysis of the environment Kuznets curve hypothesis, Energy Economics, 44, pp. 47-62.

Panayotou, T. (1992), Environmental Kuznets Curves: Empirical Tests and Policy Implications, Harvard Institute for International Development, Harvard University.

Panayotou, T. (1993), Empirical tests and policy analysis of environmental degradation at different stages of economic development, Working Paper, WP238, Technology and Employment Programme, International Labour Office, Geneva.

Panayotou, T. (1995), Environmental degradation at different stages of economic development, Beyond Rio. The Environmental Crisis and Sustainable Livelihoods in the Third World.

Park, H.M. (2009), Linear regression models for panel data using SAS, Stata, LIMDEP, and SPSS, Working Paper, The University Information Technology Services Center for Statistical and Mathematical Computing, Indiana University.

Rosser, J., Jr., Rosser, B., Rosser, M. (2006), Institutional evolution of environmental management under global economic growth, Journal of Economic Issues, Vol. XL, pp. 421-429.

Schmalensee, R., Stoker, T.M., Judson, R.A. (1998), World carbon dioxide emissions: 1950-2050, Review of Economics and Statistics, 80, pp. 15-27.

Selden, T.M., Song, D. (1993), Environmental quality and development: is there a Kuznets curve for air pollution emissions?, Journal of Environmental Economics and Management, Vol. 27, No. 2, pp. 147-62.

Shafik, N., Bandyopadhyay, S. (1992), Economic growth and environmental quality: Time series and cross-country evidence, The World Development Report 1992, The World Bank, Washington.

Shafik, N. (1994), Economic development and environmental quality: an econometric analysis, Oxford Economic Papers, 46, pp. 757-773.

Stern, D.I., Common, M.S., Barbier, E.B. (1996), Economic growth and environmental degradation: the environmental Kuznets curve and sustainable development, World Development, 24, pp. 1151-1160. 
Stern, D.I. (2003), The environmental Kuznets curve, Internet Encyclopaedia of Ecological Economics, International Society for Ecological Economics, Department of Economics, Rensselaer Polytechnic Institute.

Stern, D.I. (2014), The environmental Kuznets curve: A primer, Centre for Climate Economic \& Policy Working Paper, 1404, Crawford School of Public Policy, The Australian National University.

Torras, M. (2005), Income and power inequality as determinants of environmental and health outcomes: some findings, Social Science Quarterly, Vol. 86, pp. 1354-1376.

World Bank (2009) World Development Indicators Online (WDI), World Bank. Data retrieved July 20, 2014, data.worldbank.org/indicator 